\title{
REFLEXO DA CULTURA SOBRE 0 LOCAL DE ÓBITO DE IDOSOS NO BRASIL: ESTUDO DESCRITIVO, DE 2005 A 2018
}

Bruna Fernandes; Universidade Federal do Paraná - Campus Toledo; bruufernaandes96@gmail.com Dagna Karen de Oliveira; Universidade Federal do Paraná - Campus Toledo; dagnaoliveira2015@gmail.com

Dyayne Carla Banovski; Universidade Federal do Paraná - Campus Toledo; dyayne@gmail.com Sadana Hillary Dal'Negro; Universidade Federal do Paraná - Campus Toledo; sadanadalnegro@gmail.com Kenny Regina Lehmann; Universidade Federal do Paraná - Campus Toledo; kenny.regina@ufpr.br

\section{RESUMO}

Introdução: O cuidado paliativo (CP) iniciou-se no Brasil na década de 80 e passou a ser ofertado nas Redes de Atenção à Saúde em 2016. O CP considera o processo de morrer como inerente à vida e empodera o paciente frente à escolha do local dos últimos cuidados. Objetivo: Analisar os óbitos domiciliares de idosos no Brasil e os principais capítulos da Classificação Internacional de Doenças notificados. Metodologia: Estudo descritivo, transversal e retrospectivo dos óbitos de idosos de 2005 a 2018 registrados pelo Ministério da Saúde (MS). Resultados: De 2005 (28,5\%) a 2018 (21,59\%) ocorreu uma redução dos óbitos residenciais. As principais causas de óbito englobam as doenças do aparelho circulatório, respiratório e neoplásicas, tanto em domicílio quanto em outros locais. Conclusão: Embora haja uma redução dos óbitos residenciais, pesquisas mostram uma preferência por morrer em casa quando há CP. Entretanto, nosso sistema de saúde não está organizado de forma a permitir suporte individualizado e universal, mesmo que as principais causas de óbitos decorram de doenças elegíveis a essa assistência. Além disso, a queda dos registros de óbitos domiciliares também é reflexo da cultura nacional, na qual a assistência médica tem caráter curativo. Visando ampliar o número de leitos domiciliares, o MS investiu em políticas públicas, como a Portaria no 2.529/2006, instituindo a Internação Domiciliar, porém essa medida isolada não foi suficiente, sendo necessário também desmistificar o $\mathrm{CP}$ como abandono de assistência e reafirmá-lo como cuidado essencial não só no evento de morte como em todo o processo de morrer.

Palavras-chave: Atenção à Saúde; Cuidados paliativos; Registros de mortalidades 